\title{
DETECCIÓN GENÓMICA Y EXPRESIÓN DE PÉPTIDOS ANTIMICROBIANOS (? - y ? -DEFENSINAS) EN MUCOSA INTESTINAL DE CRÍAS DE ALPACA (Vicugna pacos)
}

\author{
Genomic Detection and Expression of Antimicrobials Peptides (? - ANd ? - \\ Defensins) in Intestinal Mucous of Newborn Alpaca (Vicugna pacos)
}

\author{
Juan More B. ${ }^{1}$, Alberto Manchego S. ${ }^{1,2}$, Nieves Sandoval C. ${ }^{3}$, Mercy Ramírez V. ${ }^{1}$, \\ Danilo Pezo C. ${ }^{4}$, Kim Lam Chiok C. ${ }^{1}$, Hermelinda Rivera G. ${ }^{1}$
}

\section{Resumen}

\begin{abstract}
El objetivo del presente estudio fue determinar la presencia genómica de ? - y ?defensinas (Defa 8 y??-def alp) y sus niveles de expresión como ARN mensajeros, en muestras de mucosa intestinal de crías alpaca. Se colectaron muestras de yeyuno y sangre de 30 animales de 0 a 45 días de edad. Se extrajo el ADN genómico y los ARN mensajeros para el análisis por PCR y RT-PCR tiempo real, respectivamente. La prueba de PCR convencional determinó que todas las muestras amplificaron un segmento genómico de entre 800 y 900 pb correspondiente a una Defa 8, y el 90\% (27/30) de las muestras amplificó un segmento esperado de 300 a 350 pb para ?-defalp y dos bandas adicionales de 800 a 900 pb, evidenciados en la electroforesis en gel de agarosa. La detección de ARN mensajeros por RT-PCR tiempo real se realizó en base al análisis de las curvas de amplificación $(\mathrm{Ct})$ y curvas de disociación $(\mathrm{Tm})$ de los productos amplificados. Las Cts de los amplificados de Defa 8 estuvieron entre 25.1 y 39.5 ciclos, con un promedio de $36.4 \pm 1.9$, y las Tm entre 79.1 y $85.7^{\circ} \mathrm{C}$. Las Cts de los amplificados de ?-def alp estuvieron entre 22.7 y 36.8 ciclos, con un promedio de $32.4 \pm 3.3$, y las Tm tuvieron un rango de 71 a 81.9 ${ }^{\circ} \mathrm{C}$. Los niveles de expresión se determinaron por cuantificación relativa en base al método de Ct comparativo. Los resultados mostraron niveles crecientes de Defa 8 y ? - defalp hasta la $3^{\mathrm{a}}$ semana, disminuyendo entre la $4^{\mathrm{a}}$ y $6^{\mathrm{a}}$ semana. Los resultados demuestran la presencia genómica y expresión de ? -y ?-defensinas en el yeyuno de las crías de alpaca menores de 45 días de edad.
\end{abstract}

Palabras clave: camélidos sudamericanos, péptidos antimicrobianos, PCR, RT-PCR tiempo real, cuantificación relativa

\footnotetext{
${ }^{1}$ Laboratorio de Microbiología y Parasitología Veterinaria, ${ }^{3}$ Laboratorio de Histología, Embriología y Patología Veterinaria, Facultad de Medicina Veterinaria, Universidad Nacional Mayor de San Marcos, Lima

${ }^{4}$ Estación Experimental del Instituto Veterinario de Investigaciones Tropicales y de Altura-Maranganí (IVITA-Maranganí), Universidad Nacional Mayor de San Marcos

${ }^{2}$ E-mail: amanchegos@unmsm.edu.pe
} 


\begin{abstract}
The aim of this study was to determine the presence of genomic ?-and?-defensins (bovine enteric beta defensin - ?-def alp - and Defa 8 respectively) and their levels of expression as messenger RNA in samples of intestinal mucosa of newborn alpacas. Samples of jejunum of 30 animals from 0 to 45 days of age were collected. Genomic DNA and mRNA were extracted for PCR analysis and real-time RT-PCR respectively. All samples amplified a single DNA segment (between 800 and $900 \mathrm{pb}$ ) by PCR which corresponds to the alpha defensin 8 (defa 8), while 90\% (27/30) amplified a segment expected 300-350 pb for ?-def alp and two additional bands of 800-900 pb evidenced by agarose gel electrophoresis. The detection of mRNAs by real time RT-PCR was performed based on Cycle threshold $(\mathrm{Ct})$ analysis and Melting temperature $(\mathrm{Tm})$ of the amplified products. The Cts for defa 8 products were found between 25.1 and 39.5 cycles with an average of $36.4 \pm 1.9$, and the Tm of the amplicons was located between 79.1 and $85.7^{\circ} \mathrm{C}$. The $\mathrm{Cts}$ for ?-def alp were found between 22.7 and 36.8 cycles with an average of $32.4 \pm 3.3$ and the $\mathrm{Tm}$ of these amplified products ranged between 71 and $81.9^{\circ} \mathrm{C}$. The expression levels were determined by relative quantification based on the comparative $\mathrm{Ct}$ method. The results showed increased levels of defa 8 and ?-def alp until the $3^{\text {rd }}$ week of age, and a decline between the $4^{\text {th }}$ and $6^{\text {th }}$ week of age. The results demonstrate the genomic presence and expression of? - and ?-defensins in the jejunum of alpacas younger than 45 days old.
\end{abstract}

Key words: South American camelids, antimicrobials peptides, PCR, real time RT-PCR, relative quantification

\section{INTRODUCCIÓN}

La inmunidad innata de mucosas es muy importante como barrera de defensa inicial frente a organismos patógenos (Ganz, 2003), ya que sus componentes permiten la eliminación de microorganismos que entran en contacto con los organismos superiores a través de las superficies corporales; siendo el tracto intestinal, la principal vía de ingreso de patógenos causantes de problemas entéricos (Jenssen et al., 2006) que ocasionan altos índices de mortalidad en crías de alpacas.

Los péptidos antimicrobianos son parte importante de la respuesta inmune inicial, no solo porque median la eliminación de patógenos en forma directa, sino que intervienen en los mecanismos de respuesta inmune tardíos, permitiendo el montaje y el mantenimiento de la respuesta inmune adquirida (Ganz, 2003; Sahl et al., 2005; Jenssen et al., 2006). Las defensinas son la familia de péptidos antimicrobianos más grande y más estudiada; son proteínas pequeñas de bajo peso molecular y de carácter catiónico, que tienen actividad como proteínas formadoras de poros en las membranas de los microorganismos, entre otros blancos celulares (Jennsen et al., 2006). Se ha demostrado su presencia génica y su expresión en roedores, bovinos y primates. En los últimos años, se está incluyendo a las defensinas dentro de nuevos protocolos terapéuticos multimodales contra enfermedades infecciosas de humanos y mamíferos domésticos, con resultados alentadores (Kamysz et al., 2003).

Aun no se ha determinado la presencia genómica de las defensinas ni su expresión en camélidos sudamericanos. Debido a esto, el presente trabajo buscó determinar su presencia (? - y ?-defensinas) en el genoma de las alpacas y evaluar su expresión relativa durante los primeros 45 días de edad. Estos hallazgos permitirán aportar al conocimiento de la respuesta inmune innata de mucosas en esta especie, y posteriormente, contribuir a la mejora del manejo terapéutico de los problemas entéricos en esta especie. 
Cuadro 1. Secuencias de primers de a-defensina (Defa 8) y GAPDH (gliceraldehído 3 fosfato deshidrogenasa) empleados en el estudio

\begin{tabular}{ccc}
\hline Gen & Forward & Reverse \\
\hline Defa 8 & GAAGACACTTGTCCTCCTTTCTG & AATAGACCTGGACGACAGGACC \\
GAPDH & GTGAAGGTCGGAGTGAACG & GAGATGATGACCCTCTTGGC \\
\hline
\end{tabular}

Cuadro 2. Secuencia de los cebadores de B-defensina diseñado en el estudio

\begin{tabular}{cccccc}
\hline Cebador & Inicio & Tamaño & Tm & GC\% & Secuencia \\
\hline Forward & 653 & 20 & 60.07 & 50.00 & tccatagatgggacacagca \\
Reverse & 902 & 20 & 59.99 & 55.00 & tcctctcttcctgccactgt \\
\hline
\end{tabular}

\section{Materiales y Métodos}

\section{Animales y Muestras}

Se emplearon 30 crías de alpacas constituidos en 7 grupos de 4 a 5 animales por grupo de 0 a 45 días de edad, variedad Suri y Huacaya, sin distinción de sexo, del distrito de Maranganí, provincia de Canchis, Cusco.

Para el uso de animales de experimentación se contó con la autorización N. ${ }^{\circ} 2009$ 001 del Comité de Ética y Bienestar Animal de la Facultad de Medicina Veterinaria de la Universidad Nacional Mayor de San Marcos. Los animales fueron sacrificados empleando un protocolo de $1.5 \mathrm{mg} / \mathrm{kg}$ de xilacina (Rompun ${ }^{\circledR}$ ) y $7.5 \mathrm{mg} / \mathrm{kg}$ de ketamina (Vetalar ${ }^{\circledR}$ ) vía intramuscular (Urquieta et al., 1992) seguido por una sobredosis de $50 \mathrm{mg} /$ $\mathrm{kg}$ vía endovenosa de pentobarbital sódico (Halatal®).

Se obtuvieron secciones de yeyuno de $2 \mathrm{~cm}$ de longitud, eliminando el contenido intestinal mediante lavado con suero fisiológico al $0.9 \%$. Se extrajo la mucosa intestinal mediante un raspado profundo. Además, se colectó $1 \mathrm{ml}$ de sangre entera, a partir del cual se extrajo los leucocitos sanguíneos por el método de gradiente de Ficoll (Morgan y Darling, 1993). Las muestras se almacenaron en nitrógeno líquido hasta su procesamiento.

Se usaron muestras pareadas para la detección genómica (ADN genómico) y para el análisis de expresión (ARN mensajeros). Los leucocitos sanguíneos se utilizaron solo para la detección génica.

\section{Cebadores}

Para la detección de ? -defensina, Defa 8 , se empleó el juego de cebadores usado por Patil et al. (2004) en un estudio comparativo de genes de ?-defensinas en roedores y humanos. Además, se utilizaron cebadores específicos para GAPDH (gliceraldehído 3 fosfato deshidrogenasa) como control interno (Cuadro 1). El tamaño de los productos para Defa 8 de ADN genómico es de 840 pb y del ADNc (ADN complementario del ARN mensajero) de $258 \mathrm{pb}$. El tamaño de los amplificados de GAPDH es de $356 \mathrm{pb}$.

El diseño de primers para ?-defensina (?- def alp) se hizo a partir de secuencias de ?-defensina de bovino (Bos taurus) del banco de genes del National Center for Biotechnology Information (NCBI) (http:// www.ncbi.nlm.nih.gov/gene/), escogiéndose 
aquella con número de acceso AF016539.1. Para realizar el diseño de cebadores se utilizaron los programas Primer3 output y primer BLAST (Cuadro 2).

El tamaño de los productos amplificados con el set de cebadores ?-def alp es de $226 \mathrm{pb}$. El análisis del producto predecible tiene un $100 \%$ de identidad con la secuencia de B. taurus ?-defensina entérica (AF016539.1), 92\% para la secuencia de la ?-defensina 5 de B. taurus (AJ278799.1) y 90\% para la secuencia de ?-defensina 4 de B. taurus (AF008307).

\section{Detección Genómica de ? - y ?-defensinas}

Extracción de ADN Genómico. Se utilizó el Kit DNeasy ${ }^{\circledR}$ Blood and Tissue (Qiagen), siguiendo las especificaciones del fabricante. Se tomó $250 \mu \mathrm{l}$ de muestra (raspado intestinal y capa flogística) y $20 \mu \mathrm{l}$ de Proteinasa $\mathrm{K}(20 \mathrm{mg} / \mathrm{ml})$. Se adicionó $200 \mu \mathrm{l}$ de buffer AL a cada muestra; se mezcló e incubó a 56 ${ }^{\circ} \mathrm{C}$ por 10 min para lisar las células. Se agregó $200 \mu \mathrm{l}$ de etanol absoluto y se mezcló. Se adicionó $600 \mu \mathrm{l}$ de la mezcla anterior en una columna de membrana de sílica colocado en un tubo de colección de $2 \mathrm{ml}$ (DNeasy mini spin) y se centrifugó. Se descartó el fluido y el tubo de colección. Se realizaron dos lavados con centrifugaciones sucesivas con los buffer del kit (AW1 y AW2) para eliminar material residual. Se colocó la columna en un tubo nuevo y se agregó $200 \mu \mathrm{l}$ de buffer AE sobre la membrana de la columna para recuperar el ADN, el cual fue almacenado en nitrógeno líquido hasta su procesamiento posterior.

Reacción en Cadena de la Polimerasa $(P C R)$. Se empleó el kit Go taq ${ }^{\circledR}$ Hot Start Colorless Master Mix (Promega). Se adicionó $2.5 \mu 1$ de ADN extraído en una mezcla de reacción conteniendo $12.5 \mu 1$ de MasterMix Go taq $(2 \mathrm{x}), 0.5 \mu \mathrm{l}$ de cada cebador $(10 \mu \mathrm{M})$, y $9.5 \mu \mathrm{l}$ de agua libre de nucleasas, para obtener un volumen de reacción final de $25 \mu$ l. El protocolo fue el siguiente: Desnaturalización inicial de $94{ }^{\circ} \mathrm{C}$ por $2 \mathrm{~min}$, segui- do con 40 ciclos de $94{ }^{\circ} \mathrm{C}$ por $20 \mathrm{~s}, 55^{\circ} \mathrm{C}$ por $20 \mathrm{~s}$ y $72{ }^{\circ} \mathrm{C}$ por $40 \mathrm{~s}$. Luego se realizó una extensión final a $72{ }^{\circ} \mathrm{C}$ por $5 \mathrm{~min}$, para acabar la reacción a $4^{\circ} \mathrm{C}$. Se usó el termociclador PTC 200 (BioRad). Los productos fueron analizados en gel de agarosa al $1 \%$, teñidos con bromuro de etidio y visualizados en un transiluminador UV.

\section{Expresión de ? - y ?-defensinas}

Para el análisis de la expresión se extrajo los ARN mensajeros totales de las muestras de mucosa intestinal, para ser analizados por RT-PCR tiempo real.

Extracción de ARN mensajeros. Se utilizó el kit $S V$ Total RNA Isolation System (Promega), siguiendo las especificaciones del fabricante. Se colocó $250 \mu 1$ de las muestras en tubos eppendorf de $2 \mathrm{ml}$, se agregó $175 \mu \mathrm{l}$ de buffer de lisado + BM, $350 \mu$ l de buffer de dilución (RDA), se mezcló y se centrifugó. Se transvasó $750 \mu 1$ de sobrenadante resultante, se adicionó $200 \mu 1$ de etanol al 95\%, y se mezcló empleando el vórtex. Luego, se transfirió $700 \mu 1$ de la mezcla al cartucho preinsertado al tubo de colección del kit (SV Total RNA Isolation System). Se centrifugó a $12000 \mathrm{G}$ por $15 \mathrm{~s}$ a temperatura ambiente. Se realizaron dos pasos de lavados y centrifugados, con los buffer del kit, para eliminar el debris celular. Se colocó el cartucho en el tubo de lavado del kit (SV Total RNA Isolation System). Se incubó con DNAsa, para eliminar el ADN, se paró la reacción y se lavó con wash buffer. Se recuperó el ARN mensajero total y se almacenó en nitrógeno líquido.

RT-PCR tiempo real. Para la transcripción reversa de los ARN mensajeros a ADN complementario, el cual sirvió como templado para el PCR tiempo real, se utilizó el kit cDNA superscript III supermix (Invitrogen), siguiendo las especificaciones del fabricante. Se usó $10 \mu 1$ de Reaction mix (2x), $2 \mu 1$ de enzima MULV-RT (1U), $7 \mu 1$ de agua y se agregó 1 $\mu 1$ del ARN extraído, para completar un volumen de reacción de $20 \mu \mathrm{l}$. Se usó el siguiente 
protocolo: $25^{\circ} \mathrm{C}$ por $10 \mathrm{~min}, 50{ }^{\circ} \mathrm{C}$ por 30 min, $85^{\circ} \mathrm{C}$ por 5 min y luego a $4^{\circ} \mathrm{C}$. Se añadió $1 \mu \mathrm{l}$ de RNasa $\mathrm{H}$ y se incubó a $37^{\circ} \mathrm{C}$ por $20 \mathrm{~min}$.

Para el PCR tiempo real se utilizó el kit Sybr green super mix (Invitrogen). La mezcla de reacción contenía $10 \mu \mathrm{l}$ de master mix sybr green $(2 \mathrm{x}), 0.4 \mu \mathrm{l}$ de cada cebador (10 $\mu \mathrm{M}), 1 \mu \mathrm{l}$ de ROX, $7.2 \mu \mathrm{l}$ de agua libre de nucleasas y $1 \mu 1$ del ADN complementario de los mensajeros totales (ADNc). El protocolo empleado fue: $50{ }^{\circ} \mathrm{C}$ por $2 \mathrm{~min}, 95^{\circ} \mathrm{C}$ por 10 min, seguido de 40 ciclos de $95^{\circ} \mathrm{C}$ por $15 \mathrm{~s}$ y $60{ }^{\circ} \mathrm{C}$ por $1 \mathrm{~min}$. Los resultados se analizaron en base a la curva de amplificación $(\mathrm{Ct})$ y la temperatura de disociación $(\mathrm{Tm})$ de los productos amplificados con el software Opticon Monitor 2.1.

\section{Cuantificación Relativa de ? - y ? - defensinas}

Se realizó la cuantificación relativa en base al método Ct comparativo (Pfaffl, 2001; Rebrikov y Trofimov, 2006). En este método, los resultados se presentan como número de veces con respecto a un calibrador (individuo con cantidades basales de expresión del gen a analizar). De esta forma se obtuvo los niveles de expresión de ? - y ?-defensinas (Defa 8y ?- def alp) con respecto a un calibrador, considerando como tal a los animales de 0 días de edad. Los animales fueron agrupados por semanas de edad, considerando tres animales en promedio por grupo etario debido a la poca disponibilidad de animales. El grupo calibrador constó de tres animales.

\section{Resultados}

\section{Detección Genómica de ? -y ? - defensinas}

Al realizar un PCR con el set de cebadores GAPDH usado como control interno de las muestras se encontró que en el 100\% (30/30) de las muestras se amplifica una región del ADN de 300 pb en promedio.

Los resultados de PCR mostraron que el total de las muestras (30/30), con el set de cebadores Defa 8 evidenció que el producto de ADN amplificado tiene un peso molecular entre 800 y 900 pb (Fig. 1).

Con el set de cebadores ?- def alp se observó tres productos específicos a partir de los leucocitos de las muestras de sangre de alpacas en el 90\% (27/30) de las muestras, con un tamaño de 900,800 y 350 pb. El $10 \%$ restante (3/30) presentó los dos productos de tamaño mayor ( 800 y $900 \mathrm{pb}$ ). Con el ADN de la mucosa intestinal se obtuvo los mismos resultados (Fig. 2).

\section{Expresión de ? - y ?- defensinas}

En la expresión de ARN mensajeros de $G A P D H$, los resultados del RT-PCR tiempo real mostraron que todas las muestras de mucosa intestinal (30/30) tuvieron una curva de amplificación ( $\mathrm{Ct}$ ) antes de los 40 ciclos. Los Ct se muestran considerando solo un valor decimal y varían dentro de un rango de 21.4 a 30.9 ciclos. La temperatura de disociación de los productos indica un producto específico por animal y dos productos específicos en la población muestreada. El 73.3\% (22/30) de los productos tuvieron una temperatura de disociación entre 83.3 y $83.9^{\circ} \mathrm{C}$, y el $26.7 \%$ (8/30) restante entre 80.9 y $81.5^{\circ} \mathrm{C}$ (Fig. 3).

En la expresión de ARN mensajero de ? -defensina, el análisis mostró curvas de amplificación con un $\mathrm{Ct}$ (cycle threshold, ciclo umbral) entre 25.1 y 39.5 ciclos con un promedio de $36.4 \pm 1.9$. El análisis de la curva de disociación mostró un pico único, con un leve ruido de fondo y una temperatura de disociación entre 79.1 y $85.7^{\circ} \mathrm{C}$ (Fig. 4).

Los resultados de la expresión de ARN mensajeros de ?-defensina mostraron que la temperatura de disociación tuvo un rango de 71 a $81.9^{\circ} \mathrm{C}$ (Fig. 5), y las curvas de ampli- 
ficación de 22.7 y 36.8 ciclos con un promedio de $32.4 \pm 3.3$.

En la cuantificación relativa de ?- y ?defensinas, los niveles de expresión relativos al calibrador (animales de 0 días de edad) de cada uno de los grupos etarios, mostraron una expresión creciente en las tres primeras semanas de edad y una caída en la expresión entre la $4^{\mathrm{a}}$ y $6^{\mathrm{a}}$ semana (Fig. 6 y 7).

\section{Discusión}

Se determinó la presencia de los genes de ? ? ?-defensinas en muestras de mucosa intestinal y sangre de alpacas, y se ha establecido su expresión en los tejidos intestinales. Estos péptidos, si bien han sido demostrados en otros mamíferos como bovinos, ratones, ratas, monos y humanos (Patil et al., 2004), no se había determinado su presencia en los camélidos sudamericanos.

Los productos de ?-defensinas amplificados de segmentos génicos con cebadores diseñados en especies filogenéticamente distantes con los camélidos (Tarver et al., 1998), demuestran que si bien existen diferencias genéticas entre estas especies, las defensinas son componentes del sistema inmune innato, evolutivamente conservados dentro de las especies mamíferas (Ganz, 2003; Patil et al., 2004) (Fig. 1).

En el mamífero, las defensinas se agrupan en familias, de acuerdo a la presencia de secuencias conservadas presentes (Ganz, 2003). De acuerdo a esto, el análisis BLAST muestra que la secuencia empleada en el presente estudio tiene un alto grado de identidad (>90\%) con otras secuencias de defensinas genéticamente relacionadas, como la beta defensina 4 y 5 de bovinos. Además, hubo otros dos productos que fueron amplificados utilizando el mismo set de cebadores (Fig. 2), como ha sido demostrado en otros estudios (Tarver et al., 1998). Esto puede deberse a que el segmento amplificado es una secuen- cia conservada dentro de los tres segmentos amplificados por PCR que pueden ser de los otros genes de defensinas presentes en el genoma de las alpacas. Este supuesto debería ser corroborado por secuenciamiento nucleotídico de los productos encontrados.

El gen $G A P D H$ es uno de los más usados como control interno en distintos tipos de PCR (Costa, 2004; Pinilla et al., 2008) por su poca variabilidad y su expresión constante en distintos tipos celulares; sin embargo, los resultados de RT-PCR en tiempo real de las muestras de crías de alpaca muestran dos curvas de disociación dentro de la misma población, evidenciando dos productos amplificados (Fig. 3). Esto puede deberse a la expresión de dos isoformas de ARN mensajeros del gen GAPDH, debido a mecanismos post transcripcionales que permiten la formación de dos mensajeros distintos a partir de un mismo gen.

Los resultados permiten establecer que la? - y ?-defensinas se expresaron en todos los individuos (detección de ARN mensajero) que mostraron una amplificación de un segmento del gen por PCR (del ADN). La expresión en animales de diversas edades indica que se tiene una expresión constitutiva durante la vida del animal. El ciclo umbral o curva de amplificación $(\mathrm{Ct})$ alto evidencia bajos niveles de expresión de defa 8 en la mucosa intestinal de las alpacas, considerando que una muestra con un $\mathrm{Ct}$ alto significa escasa cantidad de templado inicial en la muestra (Costa, 2004). La temperatura de disociación $(\mathrm{Tm})$ de los productos obtenidos determina una alta especificidad de los cebadores; sin embargo, en algunas muestras se observó un leve ruido de fondo, debido probablemente a una degradación de los ARN mensajeros de las muestras (Lewin, 1996).

Las diversas temperaturas de disociación de los productos de RT-PCR en tiempo real usandb los cebadores Defa 8 y ? ?def alp demostraron diversidad en los productos 


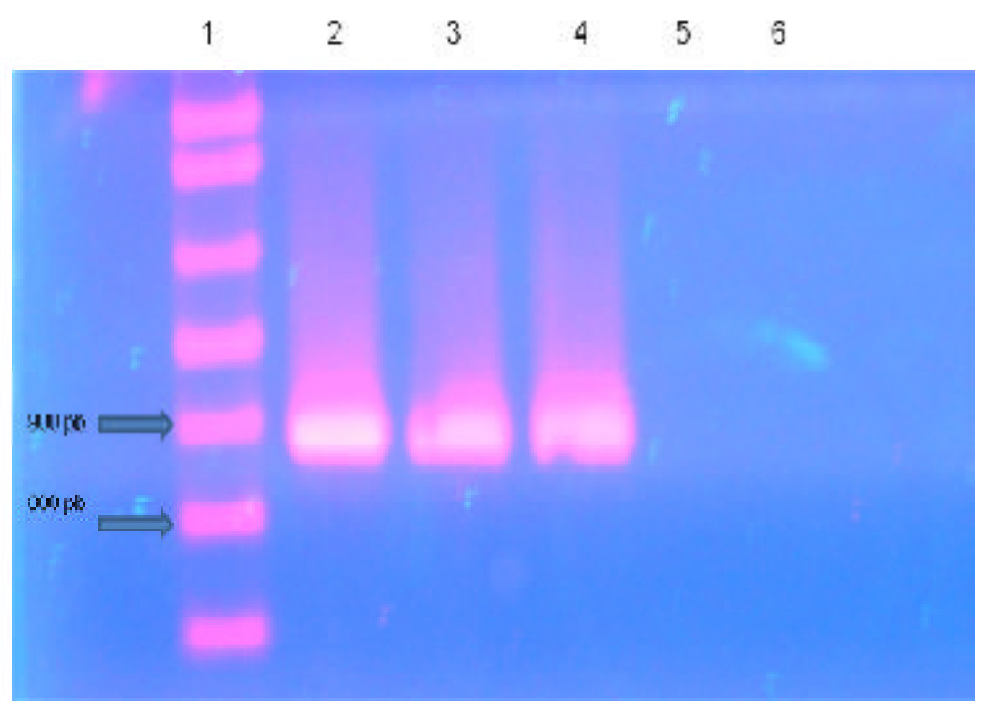

Figura 1. ADN genómico de ?-defensina. Electroforesis de un gel de agarosa al 1\%, donde se analizan los productos de PCR de muestras de ADN de leucocitos de sangre de alpacas (carril 2) y ADN de mucosa intestinal (carriles 3 y 4). El carril 1 es el marcador de peso molecular. Se visualiza un producto entre 800 y $900 \mathrm{pb}$.

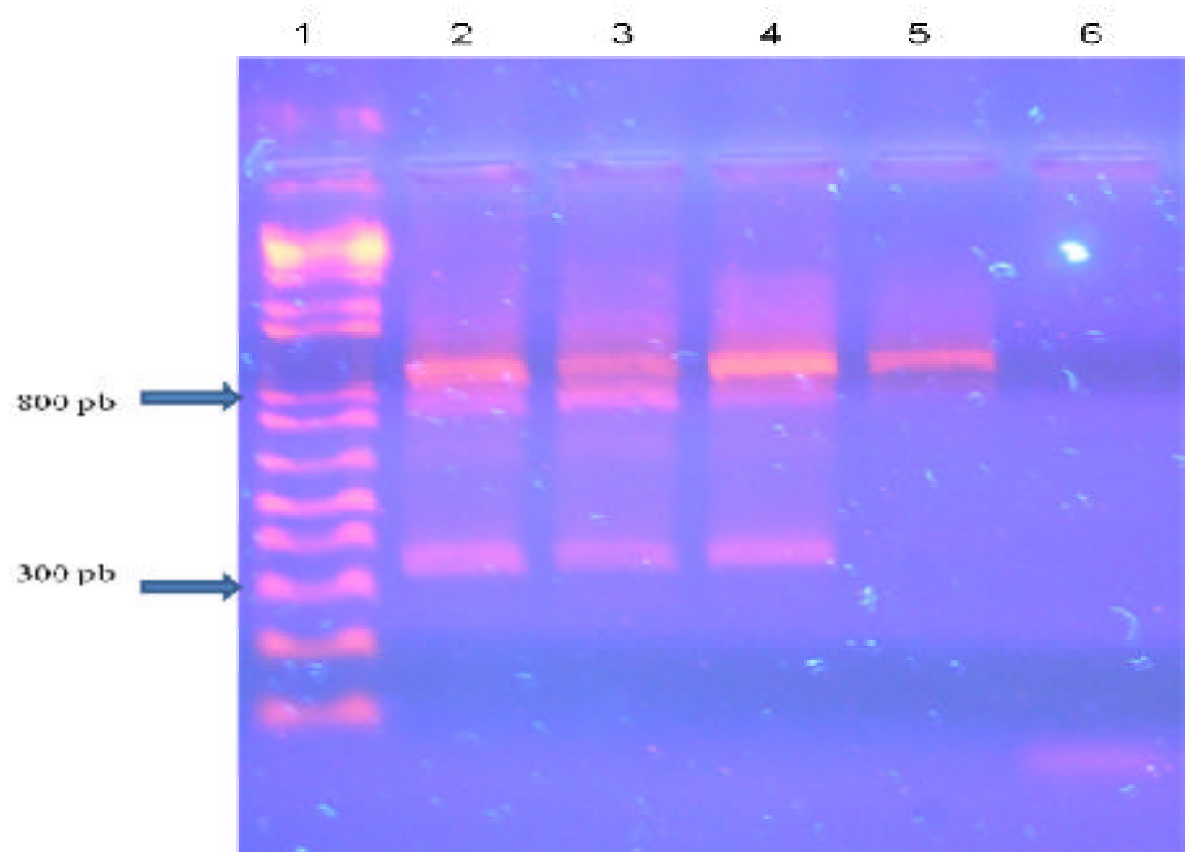

Figura 2. DNA genómico de ?-defensina (??-def alp). Electroforesis en gel de agarosa al 1\% de los productos de PCR amplificados con cebadores diseñados de ?-defensina (?? def alp). Marcador de peso molecular (carril 1); ADN de leucocitos sanguíneos de alpaca (carriles 2 y 3); ADN de mucosa intestinal de alpaca (carriles 4 y 5); control blanco de PCR sin DNA (carril 6). 


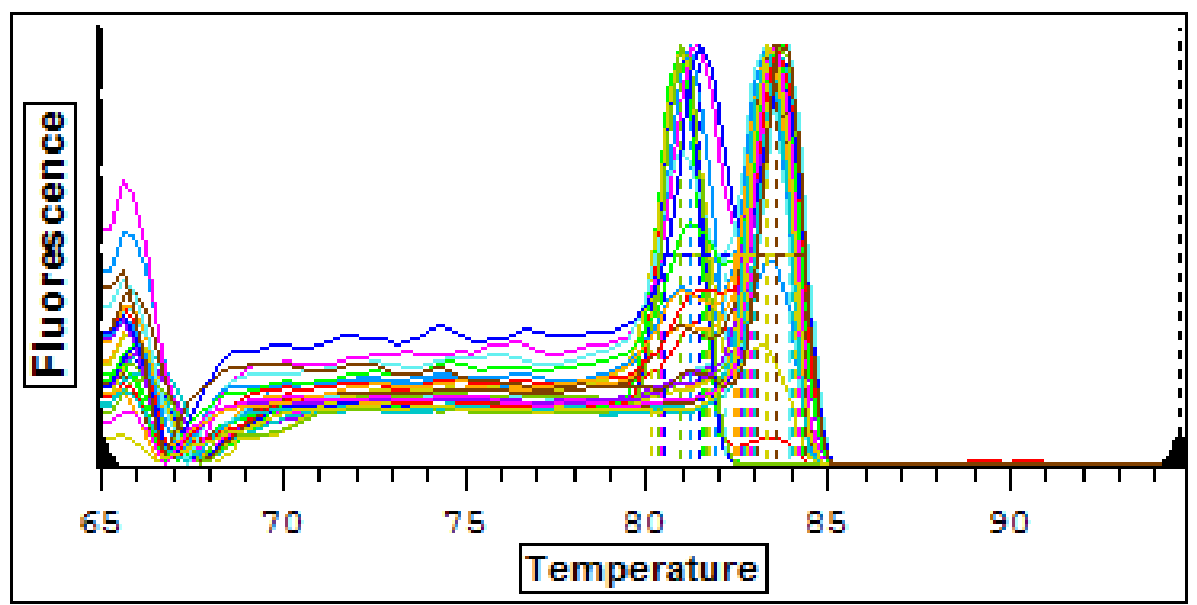

Figura 3. Temperatura de disociación (Tm) de los productos amplificados con los cebadores $G A P D H$. Nótese las dos curvas de disociación dentro de la población muestreada.

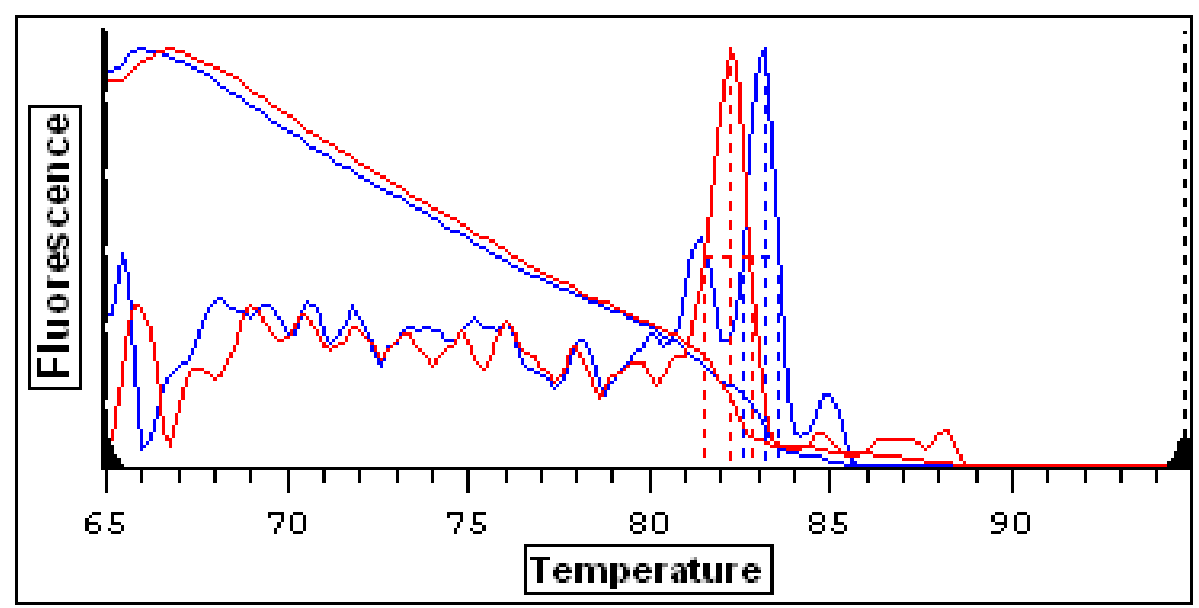

Figura 4. Temperatura de disociación de los productos amplificados por RT-PCR tiempo real de los mRNA de las muestras de mucosa intestinal de alpacas utilizando cebadores Defa 8 


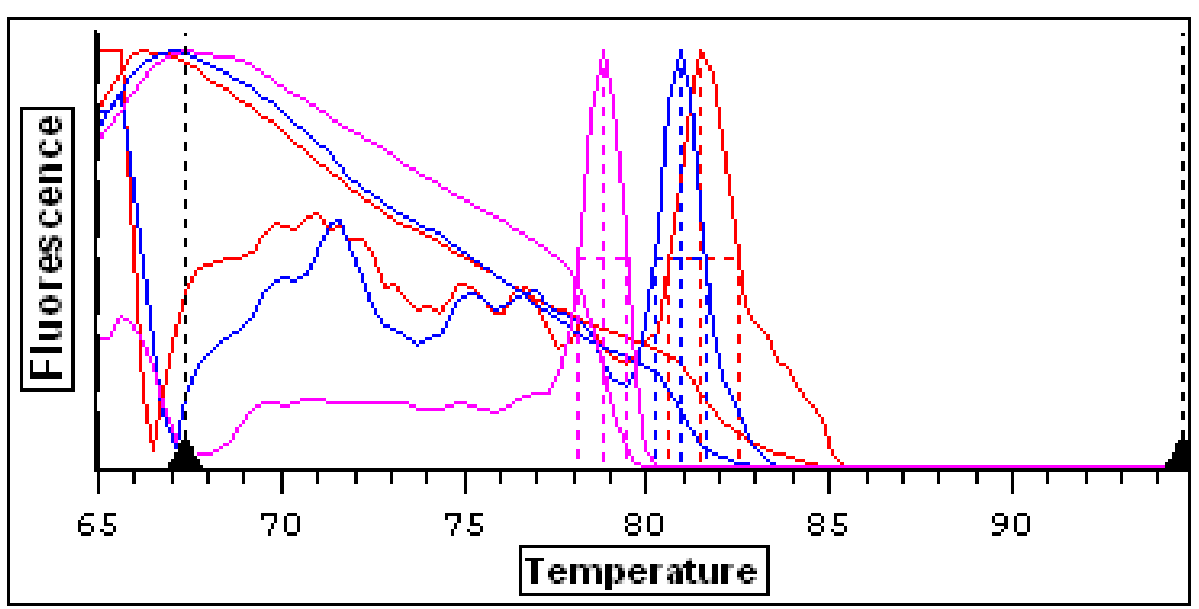

Figura 5. Temperatura de disociación de los productos amplificados con los cebadores de ?defensinas

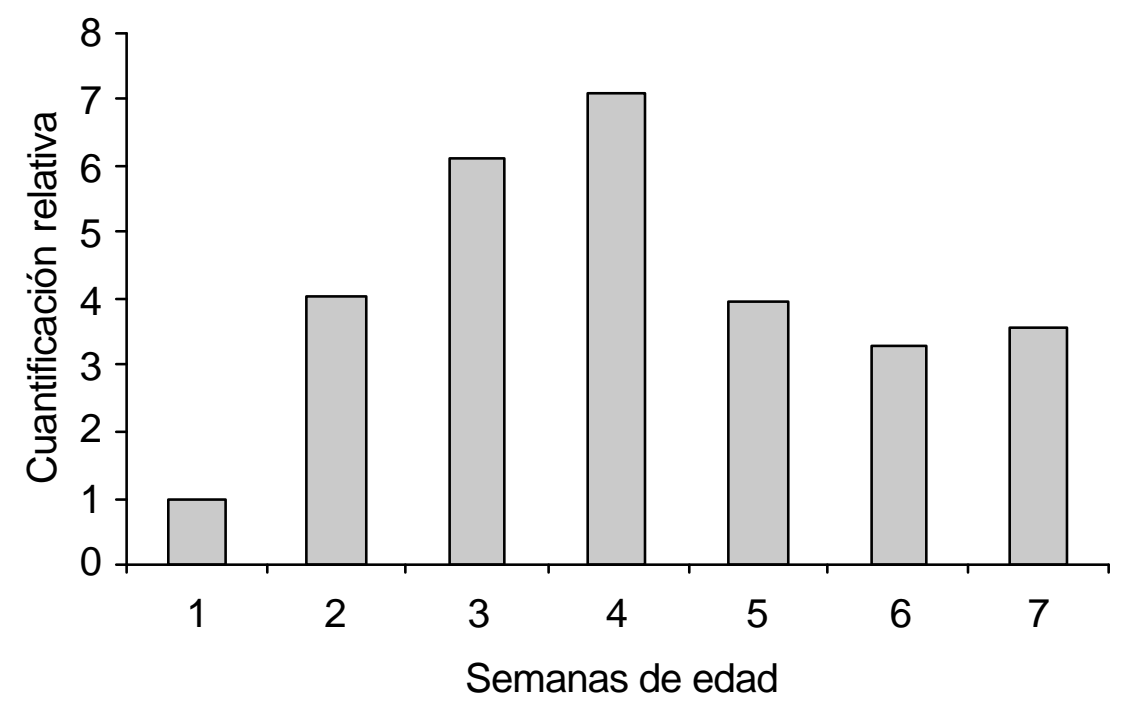

Figura 6. Niveles de expresión de ?-defensina (Defa 8) en mucosa intestinal de crías de alpaca (Vicugna pacos). La cuantificación relativa se realizó por el método $\mathrm{Ct}$ comparativo, en base al calibrador (barra 1). Las barras de 2-7 son los grupos de animales por semanas. 


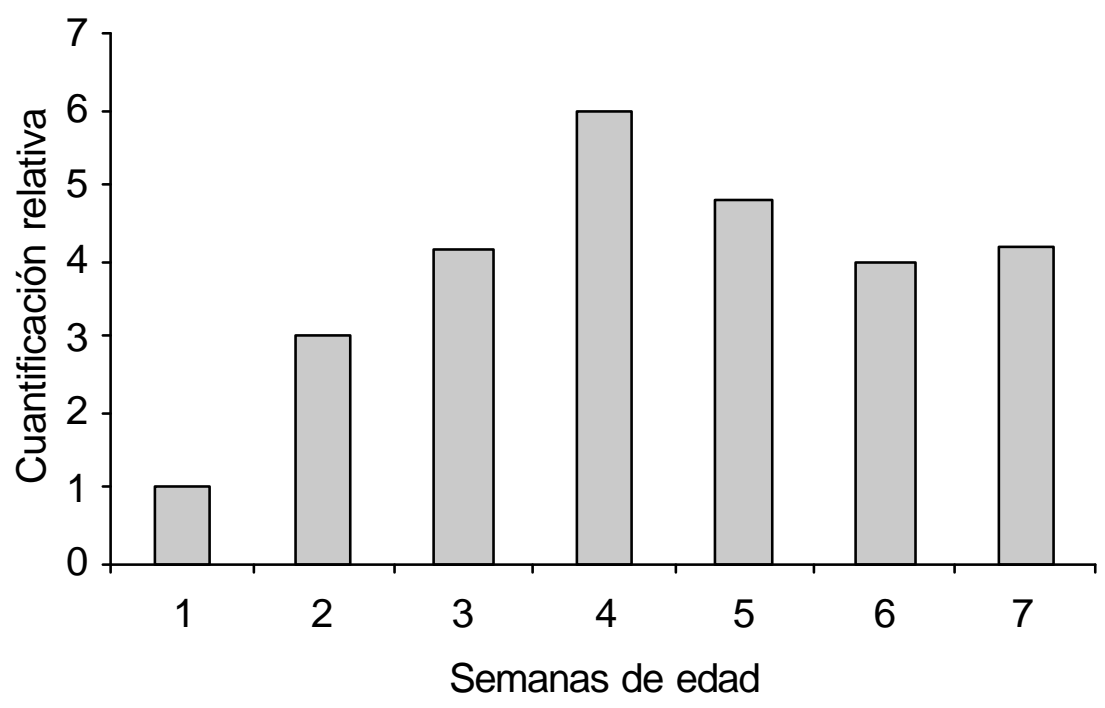

Figura 7. Niveles de expresión de ?-defensina (?- def alp) en mucosa intestinal de crías de alpaca (Vicugna pacos). La cuantificación relativa se realizó por el método Ct comparativo, en base al calibrador (barra 1). Las barras de 2-7 son los grupos de animales por semanas.

de las muestras (Fig. 4 y 5), indicando la existencia de distintos productos amplificados de defensinas (ya sea en tamaño o en la secuencia misma) dentro de una población de animales. Esto puede deberse a 1) modificaciones post transcripcionales que permiten la formación de una diversidad de ARN mensajeros a partir de un mismo gen $\mathrm{y}$, por lo tanto, la formación de diversas proteínas, como lo observado en bovinos (Ganz, 2003); 2) duplicaciones y seudogenización de los genes de defensinas (Hollox et al., 2008); y 3 ) genes de diversas defensinas que tienen regiones conservadas agrupadas en familias (Ganz, 2003). Se conoce que los organismos superiores expresan diversas proteínas que ejercen funciones en la respuesta inmunitaria, debido a modificaciones post transcripcionales (corte y empalme alternativo, recombinación de exones, etc.) que sufren los ARN mensajeros (Lewin, 1996).
La curva de expresión relativa de los productos amplificados, tanto de Defa 8 y ? def alp, en comparación con el calibrador (muestras de 0 días) (Fig. 6 y 7), solo muestra estos niveles en la población muestreada y los valores deben ser tomados únicamente como una tendencia en los niveles de expresión. Los niveles de expresión creciente podrían correlacionarse con el cambio gradual de la dieta de las alpacas, de leche a forraje; toda vez que se origina un cambio en la microflora intestinal, representando un estímulo para el sistema inmune (no solo innato sino también adaptativo), ocasionando una mayor expresión de las defensinas. Asimismo, los niveles decrecientes en la cuarta semana podrían deberse al establecimiento de la microflora y a su reconocimiento por parte del sistema inmune, estableciéndose un grado de tolerancia inmunológica que permita una expresión constante de las defensinas en estudio a partir de ese periodo. 
Los resultados, tanto de ADN genómico como de los ARN mensajeros para la ?defensina, corrobora que los primers fueron diseñados para una región de un exón. Sin embargo, en el caso de la ? ?def alp, que fue diseñada desde una región del intron entre el exón 1 y 2 de la defensina entérica del bovino, permitió la amplificación de una región desde ARN mensajeros obtenidos de alpacas. Se descarta la presencia de contaminación de ADN en el RT-PCR debido al uso de DNasas en el procesamiento de extracción de ARN y porque los productos se obtuvieron en el $100 \%$ de muestras.

El secuenciamiento nucleotídico, tanto de los productos de PCR como de RT-PCR tiempo real, de ?- y ?-defensinas, permitirá determinar la secuencia exacta del DNA genómico y de los RNA mensajeros; para así, establecer si los productos son de origen mieloide o epitelial, si existe una recombinación de exones en los RNA mensajeros o una diversificación evolutiva dentro de las defensinas estudiadas, lo cual no se pudo establecer en el presente trabajo.

\section{Conclusiones}

? $\quad$ Existen genes de ?-defensina (Defa 8) y ?-defensina (?-def alp) en las células de la capa flogística de muestras de sangre y de la mucosa intestinal de alpacas (Vicugna pacos).

? Se demostró la expresión de las defensinas Defa 8 y ?-def alp en mucosa intestinal de crías de alpacas.

\section{Agradecimientos}

Los autores agradecen a los criadores alpaqueros de las comunidades de la provincia de Canchis, Cusco, por su colaboración para la adquisición de los animales utilizados. El trabajo fue financiado por el Fondo Nacional de Innovación en Ciencia y Tecnología (FINCYTPIBAP 2008) Contrato N. ${ }^{\circ} 065-2008$.

\section{Literatura Citada}

1. Costa J. 2004. Reacción en cadena de la polimerasa (PCR) a tiempo real. Enferm Infecc Microbiol Clin 22: 299305.

2. Ganz T. 2003. The role of antimicrobial peptides in innate immunity. Integr Comp Biol 43: 300-304.

3. Hollox EJ, Barber J, Brookes A, Armour J. 2008. Defensins and the dynamic genome: What we can learn from structural variation at human chromosome band 8p23.1. Genome Res 18: 1686-1697.

4. Jenssen H, Hamill P, Hancock R. 2006. Peptide antimicrobial agents. Clin Microbiol Rev 19: 491-511.

5. Kamysz W, Okrój M, Lukasiak J. 2003. Novel properties of antimicrobial peptides. Acta Bioquim Pol 50: 461-469.

6. Lewin B. 1996. Genes VI. International Student Edition. Oxford University. 1260p.

7. Morgan S, Darling D. 1993. Cultivo de células animales. Zaragoza: Acribia. $159 \mathrm{p}$.

8. Patil A, Hughes A, Zhang G. 2004. Rapid evolution and diversification of mammalian ?-defensins as revealed by comparative analysis of rodent and primate genes. Physiol Genomics 20: 1-11.

9. Pfaffl M. 2001. A new mathematical model for relative quantification in real time RT-PCR. Nucleic Acids Res 29: 2002-2007.

10. Pinilla B, Cubillos K, Rodríguez M. 2008. Bodas de plata de la reacción en cadena de la polimerasa (PCR). NOVA 6: 1794-2470.

11. Rebrikov D, Trofimov D. 2006. RealTime PCR: A review of approaches to data analysis. Appl Biochem Microbiol 42: 455-463.

12. Sahl H, Pag U, Bonness $S$, Wagner $S$, Antcheva N, Tossi A. 2005. Mammalian defensins: structures and mechanism of antibiotic activity. J Leukoc Biol 77: 466-475. 
13. Tarver A, Clark D, Diamond G, Russell J, Erdjument-Bromage H, Tempst P, Cohen K, et al. 1998. Enteric ?defensin: molecular cloning and characterization of a gen with inducible intestinal epithelial cell expression associated with Cryptosporidium parvum infection. Infect Immun 66: 10451056.

\section{Urquieta B, Schiappacasse M, Raggi} L, Martínez R, Ferguson JG. 1992. Sedación, inmunobilización y anestesia com xilacina-ketamina em vicuña (Vicugna vicugna). Avances Cs Vet 7(2). [Internet]. Disponible en: http:// www.revistas.uchile.cl/index.php/ACV/ article/viewArticle/10425/10481 